\title{
Attempted suicide and completed suicide in traumatic spinal cord injury. Case reports
}

\author{
EC Harris ${ }^{1}$, BM Barraclough ${ }^{1}$, DJ Grundy ${ }^{2}$, ES Bamford ${ }^{2}$ and HM Inskip ${ }^{3}$ \\ ${ }^{1}$ University Department of Psychiatry, Royal South Hants Hospital, Southampton; ${ }^{2}$ The Duke of Cornwall Spinal \\ Treatment Centre, Salisbury District Hospital, Salisbury; ${ }^{3}$ MRC Environmental Epidemiology Unit, Southampton \\ General Hospital, Southampton, UK
}

Keywords: spinal cord injury; follow-up; mortality; suicide; liaison psychiatry

\section{Introduction}

Follow-up studies of spinal cord injury patients show a fourfold increase in the suicide rate. ${ }^{1}$ To examine this risk further we studied a consecutive series of 366 traumatic spinal cord injured patients from the time of their discharge from a spinal injuries unit, for a period of up to 8 years (mean 3.5 years). Attempted suicide had been the cause of the spinal injury in 11 patients $(3 \%)$.

The number of observed deaths was compared with the number expected. Expected deaths for all causes, suicide (E950-959), and undetermined death (E980989) (death from injury undetermined as accidentally or purposely inflicted) were calculated using causespecific death rates by sex for five-year age-groups and one-year calendar periods, for England and Wales, by the person-years method. ${ }^{2}$ Statistical significance was assessed using the Poisson distribution.

Thirteen deaths occurred after discharge, which was not significantly more than the 8.6 expected (SMR $151,95 \%$ CI $81-259)$. We report the two violent deaths, one suicide and one undetermined death, which together exceeded the expected of 0.25 . We also report the death from bronchitis of a woman who became tetraplegic after a suicide attempt. These three histories show how long-standing mental disorder and substance abuse prior to injury, which persisted postinjury, contributed to their deaths.

\section{Case report 1}

A 57 year old married man sustained an incomplete paraplegia at $\mathrm{L} 1$ after deliberately jumping from the first floor window of his house trying to commit suicide. A few hours earlier he had electrocuted himself by holding a live cable and burning his hands. In hospital the psychiatrist diagnosed an endogenous

Correspondence: BM Barraclough DM, University Department of Psychiatry, Royal South Hants Hospital, Southampton, England SO14 OYG depression and remarked on an alcohol intake of one bottle of wine a day. A paranoid psychosis developed after spinal surgery. This may have been an alcohol withdrawal syndrome. During rehabilitation depressive symptoms continued, partly controlled by fluvoxamine and subsequently amitriptyline. The injury improved and he was discharged home with walking aids. Two years later he hanged himself at his home during a further depressive episode. The coroner's inquest returned a suicide verdict. The death certificate did not mention the spinal cord injury or mental disorder.

\section{Case report 2}

A 45 year-old single man who lived with his brother acquired a complete tetraplegia at $\mathrm{C6} / 7$ falling forwards over roadworks while going home from a public house when drunk. There was a long history of alcohol abuse and he developed delirium tremens after admission. Binge drinking continued in hospital. He had been treated in the past with psychotherapy for a 'breakdown'.

The tetraplegia resulted from a hyper-extension injury, without detectable bony injury, to an arthritic spine based on a congenital fusion of C6/7. The tetraplegia improved from complete to walking with a frame at discharge 10 months later. Two weeks after discharge to a hostel for the physically handicapped he died. The coroner's inquest recorded death from an overdose of buprenorphine (an opioid analgesic) with a significant alcohol level and returned an open verdict (undetermined death). The death certificate did not mention the spinal cord injury or the alcohol dependence.

\section{Case report 3}

A 42 year old single woman, living by herself, incurred a complete tetraplegia at $\mathrm{C} 4 / 5$. She jumped into a canal on the instructions of hallucinatory voices telling her to 
commit suicide, climbed out and fell. The fall caused the injury. The hallucinatory voices were one of the symptoms of a schizophrenic illness, partly controlled with fluphenazine injections, lithium, carbamazepine, phenytoin, trimipramine, and care in the community. The schizophrenia, which had a marked mood component, had been present for about 18 years. A recurrence of delusions, hallucinations and disturbed conduct interfered with rehabilitation. She was discharged to a nursing home seven months postinjury, the tetraplegia little improved, and died two months later. The coroner, after a postmortem but without inquest, certified death from acute mucopurulent bronchitis, that is death from natural causes. The death certificate did not mention the spinal cord injury, nor the schizophrenia. Had there been an inquest, a suicide verdict would have been possible as the bronchitis arose from the effects of an injury less than a year before death.

\section{Discussion}

Suicide attempts caused 11 of the 366 spinal cord injuries included in this study (3\%). These eleven suicide attempts, including those of cases 1 and 3 above, were 10 jumps from a height and a pistol shot in the neck. It was clear the acts were all determined attempts at self-killing that failed. The violent methods, the sex ratio of eight men to three women and the mean age of 33 years is much closer to the statistical profile of suicide than parasuicide. ${ }^{3}$ The spinal injuries sustained were an incomplete paraplegia (five), complete paraplegia (three), complete tetraplegia (two) and complete triplegia (one). Seven were known to have harmed themselves before, six by self-poisoning and one by electrocution. All 11 had mental disorders, four of recent onset and seven long-standing, and in 10 this persisted post injury. Five had major depression, three personality disorder with substance abuse and episodic delusions and two schizophrenia. The eleventh had an acute onset depressed mood which remitted soon after the incident. The mental disorder impaired ability to take part in the spinal cord injury rehabilitation program. This was especially marked for substance abuse and schizophrenia.

The 11 had a high mortality, with two dying in the follow-up period, case 1 from suicide and case 3 from bronchitis. A third died from pneumonia 18 months after our follow-up was completed. Self-neglect resulting from serious mental disorder played a part in their deaths but none of the death certificates referred to the mental disorder or substance abuse, or even the spinal cord injury.

Other causes of death combined accounted for 11 deaths with 8.3 expected (SMR 132, 95\% CI 66-236). The difference was not statistically significant. The immediate causes of death for these eleven were respiratory infection (5), heart disease (3), cerebral haemorrhage, hypoglycaemia, urinary infection (1 each).

\section{Conclusion}

Natural causes of death within the cohort were not significantly more than expected. This corroborates recent findings ${ }^{4,5}$ which suggest that, for those who survive the acute injury, the medical effects of the injury no longer cause the high early mortality seen in the past. However, published spinal cord injury followup studies show a fourfold increase in the suicide rate over that expected in the general population. ${ }^{1}$ Our study, although small, corroborates this observation and shows that the remaining excess of early deaths probably results from self-inflicted causes. This needs to be examined further in a comprehensive, multicentre study for which the UK National Health Service is well suited. We have also shown the significance of mental disorder as a cause of spinal cord injury. Preexisting mental disorder is a likely cause of the association between spinal cord injury and raised suicide rate suggesting the need for liaison psychiatry within spinal injuries units.

\section{Acknowledgements}

The Wessex Medical Trust, The University of Southampton, The Duke of Cornwall Spinal Treatment Centre Research Fund and Knoll Pharmaceuticals (formerly of Boots plc) gave financial support. The Office of Population Censuses and Surveys National Health Service Central Register searched their mortality records and provided the death certificates. Mrs Judith Hawker assisted in searching medical records at Salisbury District Hospital.

\section{References}

1 Harris EC, Barraclough BM. Suicide as an outcome for medical disorders. Medicine 1994; 73: 281-296.

2 Breslow NE, Day NE. Statistical methods in cancer research. Volume II. The analysis of cohort studies. International Agency for Research on Cancer: Lyon 1987.

3 Kreitman NB. Aspects of the epidemiology of suicide and 'attempted suicide' (parasuicide). In: Waldenstrom J, Larsson $\mathrm{T}$, Ljungstedt $\mathrm{N}$. (eds) Suicide and attempted suicide. Skandia: Stockholm, 1972, pp 45-52.

4 DeVivo MJ, Stover SL. Long-term survival and causes of death In: Stover SL, DeLisa JA, Whiteneck GG. (eds) Spinal cord injury. Clinical outcomes from the Model Systems. Aspen Publishers, Inc: Gaithersburg, 1995, pp 289-316.

5 Whiteneck GG et al, Mortality, morbidity, and psychosocial outcomes of persons spinal cord injured more than 20 years ago. Paraplegia 1992; 30: 617-630. 